\title{
Perbedaan Penggunaan Minyak Zaitun dan Minyak VCO (Virgin Coconut Oil) dengan Kejadian Strie Gravidarum pada Ibu Nifas Hari 1-7
}

\author{
Yuli Irnawati \\ Email: yuliirnawati30@gmail.com \\ Prodi D III Kebidanan STIKES Bakti Utama Pati, Indonesia \\ Jl. Ki Ageng Selo No.15 Pati \\ Telp. (0295) 384984
}

\begin{abstract}
Abstrak
Striae gravidarum dapat dikurangi dengan penggunaan minyak zaitun. 100 g minyak ekstra virgin mengandung 14,39 mcg (sekitar 96\%) alpha tocopherol. Sedangkan pada minyak kelapa (Virgin Coconut $\mathrm{Oil}$ ) dalam $100 \mathrm{~g}$ nya hanya mengandung $0,1 \mathrm{mg}$ Vitamin E. Tujuan penelitian ini adalah untuk menganalisis perbedaan antara penggunaan minyak zaitun dan minyak kelapa terhadap kejadian strie gravidarum pada ibu hamil. Penelitian ini termasuk dalam penelitian eksperimen. Pendekatan dalam penelitian eksperimen menggunakan pendekatan positivisme-kuantitatif. Semua ibu hamil di desa Blaru pada bulan Januari-Agustus sebanyak 30 ibu hamil. Sampel dalam penelitian ini adalah $15 \mathrm{ibu}$ hamil yang menggunakan minyak zaitun dan $15 \mathrm{ibu}$ hamil yang menggunakan minyak VCO. Jenis analisa data dalam penelitian ini menggunakan Uji uji beda. Nilai rata-rata (mean) Strie Gravidarum pada ibu nifas yang diberikan minyak Zaitun adalah 3,13 dalam sehari dan standar deviasi adalah 1.642. Sedangkan nilai rata-rata (mean) Strie Gravidarum pada ibu nifas yang diberikan minyak VCO adalah 2,93 dalam sehari dan standar deviasi adalah 1.831. Hasil uji statistik dengan uji independent sample $t$ test diperoleh $p$-value $=0.007$ ( $p$ value $<\mathrm{a}=0,05$ ), hasil ini menunjukkan bahwa ada perbedaan yang signifikan antara pemberian minyak zaitun dan minyak VCO terhadap striae gravidarum pada ibu nifas.
\end{abstract}

Kata Kunci: minyak zaitun; minyak vco; strie gravidarum; ibu hamil.

\begin{abstract}
Striae gravidarum can be reduced by the use of olive oil.. $100 \mathrm{~g}$ of extra virgin oil contains 14.39 mcg alpha tocopherol. Whereas the coconut oil in $100 \mathrm{~g}$ only contains $0.1 \mathrm{mg}$ of Vitamin E. The purpose of this study was to analyze the difference between the use of olive oil and coconut oil on the incidence of strie gravidarum in pregnant women. This research is included in experimental research. All pregnant women in January to August were 30 pregnant women. The sample in this study were 15 pregnant women who used olive oil and 15 pregnant women who used VCO oil. The mean value of Strie Gravidarum in postpartum mothers given Olive oil is 3.13 in a day and the standard deviation is 1,642 . While the mean value (mean) of Strie Gravidarum in postpartum mothers who were given VCO oil was 2.93 in a day and the standard deviation was 1.831 . Statistical test results with independent sample $t$ test obtained $p$-value $=0.007(p$-value $<a=0.05)$, these results indicate that there are significant differences between the administration of olive oil and VCO oil to striae gravidarum in postpartum mothers.
\end{abstract}

Keywords: olive oil; vco oil; strie gravidarum; pregnant women; 


\section{Pendahuluan}

Salah satu perubahan yang terjadi pada ibu hamil yaitu striae gravidarum. Striae gravidarum adalah bentuk parut dari kulit karena terjadinya peregangan pada saat hamil dan kenaikan berat badan selama kehamilan.Sekitar $90 \%$ wanita memiliki striae gravidarum terutama di trimester terakhir kehamilan. Beberapa striae gravidarum menghilang dengan berjalannya waktu, sementara yang lain striae gravidarum tetap sebagai permanen. Adanya striae gravidarum yang permanen tentu akan membuat ibu khawatir, ibu akan merasa dibeberapa bagian tubuhnya tidak menarik dan terganggu dengan adanya striae gravidarum yang masih akan membekas bahkan pada kehamilan selanjutnya.

Salah satu cara untuk mengurangi kecemasan selama kehamilan karena perubahan yang terjadi pada saat kehamilan seperti striae gravidarum adalah dengan cara mengurangi keparahan terjadinya striae gravidarum. Striae gravidarum dapat dicegah atau dikurangi dengan penggunaan minyak zaitun. Minyak zaitun dipilih karena minyak zaitun kaya akan vitamin E. $100 \mathrm{~g}$ minyak ekstra virgin mengandung 14,39 mcg (sekitar 96\%) alpha tocopherol. Sedangkan pada minyak kelapa (Virgin Coconut Oil) dalam $100 \mathrm{~g}$ nya hanya mengandung $0,1 \mathrm{mg}$ Vitamin E. Vitamin E merupakan antioksidan larut lemak yang kuat, diperlukan untuk menjaga membran sel, selaput lendir dan kulit dari radikal bebas berbahaya. Selain itu, minyak zaitun mempunyai kandungan lemak tak jenuh tunggal yang lebih stabil pada suhu tertinggi dibanding minyak lain seperti minyak kelapa yang banyak mengandung lemak jenuh dimana minyak zaitun adalah salah satu minyak paling sehat untukdikonsumsi.

Berdasarkan survei awal yang dilakukan pada bulan September 2019 di Polindes Desa Blaru, yang merupakan salah satu tempat yang dikunjungi ibu nifas ketika memeriksakan kondisinya pasca melahirkan. Diperoleh data jumlah ibu nifas yang berkunjung ke Polindes sejak bulan januari 2019 adalah sebanyak 40 orang ibu nifas. Tiga puluh lima (35) ibu nifas diantaranya menyatakanmengalami tandatanda munculnya striae gravidarum dimulai sejak kehamilannya. Dari hasil wawancara yang dilakukan peneliti pada $10 \mathrm{ibu}$ nifas yang mengalami strie gravidarum, 4 ibu nifas mengatakan untuk mengurangi garis- garis yang ada di perutnya ibu mengoleskan minyak zaitun. Tiga ibu nifas mengatakan menggunakan minyak kelapa dan tiga ibu nifas lainnya mengatakan hanya membiarkan saja karena bukan suatu hal penting yang harus diperhatikan (Polindes Blaru, 2019).

\section{MetodePenelitian}

Penelitian ini termasuk dalam penelitian eksperimen. Penelitian eksperimen merupakan penelitian yang dimaksudkan untuk mengetahui ada tidaknya akibat dari "sesuatu" yang dikenakan pada subjek selidik. Eksperimen yang digunakan dalam penelitian ini termasuk eksperimen kuasi (quasi experiment) atau eksperimen semu. Sampel dalam penelitian ini adalah 15 ibu nifas di desa Blaru yang menggunakan minyak zaitun dan 15 
Jurnal Kebidanan Harapan Ibu Pekalongan

ibu nifas yang menggunakan minyak VCO. Teknik sampling dalam penelitian ini adalah total sampling.

\section{Hasil danPembahasan}

A. Hasil Penelitian

1. AnalisisUnivariat

a. Distribusi Frekuensi Berdasarkan Kasus Strie Gravidarum pada Ibu Nifas

Tabel 3.1. Distribusi Frekuensi Berdasarkan Kasus Strie Gravidarum pada Ibu Nifas di Desa Blaru Kecamatan Pati Kabupaten Pati

\begin{tabular}{ccc}
\hline Stribe Gravidarum & Jumlah & $\begin{array}{c}\text { Presentase } \\
(\mathbf{\%})\end{array}$ \\
\hline AdanfrieGravidarum & 27 & 90 \\
\hline Tidak $_{\mathrm{b}}$ Strie Gravidarum & 3 & 10 \\
\hline e Jumlah & 30 & 100 \\
\hline
\end{tabular}

Sumber : Data primer.

Tabel 3.1 menunjukkan sebagian besar responden mempunyai Strie Gravidarum sebanyak 27 orang (90\%) dan responden yang tidak mempunyai Strie Gravidarum sebanyak 3 orang (10\%). Hasil tersebut menunjukkan bahwa lebih banyak ibu nifas yang mempunyai Strie Gravidarum dibandingkan ibu nifas yang tidak mempunyai Strie Gravidarum. b. Skor Frekuensi Strie Gravidarum pada Ibu Nifas yang diberikan Minyak Zaitun dan Minyak VCO

Tabel 3.2. Rata-rata Skor Frekuensi Strie Gravidarum pada Ibu Nifas di Desa Blaru Kecamatan Pati Kabupaten Pati

\begin{tabular}{llllll}
\hline Kelompok & Variabel & $\mathrm{N}$ & mean & SD & SE \\
\hline Ibu Nifas & Strie & 15 & 2,93 & 1.831 & 0,473 \\
& Gravida & & & & \\
& rum & & & & \\
& yang & & & & \\
diberika & & & & \\
& $\mathrm{n}$ & & & & \\
& Minyak & & & & \\
& VCO & & & & \\
\hline Ibu Nifas & Strie & 15 & 3,13 & 1.642 & 0,424 \\
& Gravida & & & & \\
& rum & & & & \\
& yang & & & \\
& diberika & & & \\
& n & & & \\
& Minyak & & & \\
& Zaitun & & & \\
\hline
\end{tabular}

Tabel

menunjukkan bahwa hasil pengukuran skor frekuensi Strie Gravidarum pada ibu nifas yang diberikan minyak Zaitun diketahui rata-rata score frekuensi Strie Gravidarum pada ibu nifas adalah 3,13 dalam sehari (SD : 1.642) (SE : $0,424)$.

Sedangkan hasil pengukuran skor frekuensi Strie Gravidarum pada ibu nifas yang diberikan minyak VCO diketahui rata-rata score frekuensi Strie Gravidarum pada ibu nifas adalah 2,93 dalam sehari (SD : 1.831) (SE : $0,473)$. 
Jurnal Kebidanan Harapan Ibu Pekalongan

2. Analisis Bivariat

Tabel 3.3. Penggunaan Minyak Zaitun dan Minyak VCO pada kejadian Strie Gravidarum pada Ibu Nifas di Desa Blaru Kecamatan Pati Kabupaten Pati

\begin{tabular}{|c|c|c|c|c|c|}
\hline Kelompok & Variabel & $\mathrm{n}$ & mean & SD & $\begin{array}{c}P \\
\text { value }\end{array}$ \\
\hline $\begin{array}{c}\text { Ibu } \\
\text { Nifas }\end{array}$ & $\begin{array}{c}\text { Strie } \\
\text { Gravidarum } \\
\text { yang } \\
\text { diberikan } \\
\text { Minyak } \\
\text { VCO }\end{array}$ & 15 & 2,93 & 1.831 & \multirow{2}{*}{0,007} \\
\hline $\begin{array}{c}\text { Ibu } \\
\text { Nifas }\end{array}$ & $\begin{array}{c}\text { Strie } \\
\text { Gravidarum } \\
\text { yang } \\
\text { diberikan } \\
\text { Minyak } \\
\text { Zaitun }\end{array}$ & 15 & 3,13 & 1.642 & \\
\hline
\end{tabular}

Tabel 3.3 menunjukkan bahwa nilai rata-rata (mean) Strie Gravidarum pada ibu nifas yang diberikan minyak Zaitun adalah 3,13 dalam sehari dan standar deviasi adalah 1.642. Sedangkan nilai rata-rata (mean) Strie Gravidarum pada ibu nifas yang diberikan minyak VCO adalah 2,93 dalam sehari dan standar deviasi adalah1.831.

Hasil uji statistik dengan uji independent sample $t$ test diperoleh $\quad p$-value $=0.007 \quad(p$ value $<\mathrm{a}=0,05), \quad$ hasil ini menunjukkan bahwa ada perbedaan yang signifikan antara pemberian minyak zaitun dan minyak VCO terhadap striae gravidarum pada ibu nifas.

\section{B. Pembahasan}

1. AnalisisUnivariat

\begin{tabular}{lr} 
a. Distribusi & Frekuensi \\
Berdasarkan & \multicolumn{2}{c}{ Strie } \\
Gravidarum & \\
$\quad$ Hasil & penelitian \\
menunjukkan & dari total
\end{tabular}

responden $\quad 30 \quad(100 \%)$ sebagian besar responden mempunyai Strie Gravidarum sebanyak 27 orang $(90 \%)$ dan responden yang tidak mempunyai Strie Gravidarum sebanyak 3 orang $(10 \%)$. Hasil tersebut menunjukkan bahwa lebih banyak ibu nifas yang mempunyai Strie Gravidarum dibandingkan ibu nifas yang tidak mempunyai Strie Gravidarum.

Striaegravidarum dapat muncul di abdomen, payudara, paha ataupun lengan bagian atas, dan nampak jelas mulai bulan ke 6-7 kehamilan. Guratan halus ataupun kasar ini dapat muncul pada sebagian wanita hamil, berkenaan dengan tingkat elastisitas kulit dan penambahan berat badan (deposit lemak). Beberapa striae gravidarum menghilang dengan berjalannya waktu, sementara yang lain striae gravidarum tetap sebagai permanen. Adanya striae gravidarum yang permanen tentu akan membuat ibu khawatir, ibu akan merasa dibeberapa bagian tubuhnya tidak menarik dan terganggu dengan adanya striae gravidarum yang masih akan membekas bahkan pada kehamilan selanjutnya. 
Jurnal Kebidanan Harapan Ibu Pekalongan

b. Skor Frekuensi Strie Gravidarum pada Ibu Nifas yang diberikan Minyak Zaitun dan Minyak VCO.

Hasil penelitian menunjukkan bahwa hasil pengukuran skor frekuensi Strie Gravidarum pada ibu nifas yang diberikan minyak zaitun diketahui rata-rata score frekuensi Strie Gravidarum pada ibu nifas adalah 3,13 dalam sehari (SD : 1.642) (SE: 0,424). Sedangkan hasil pengukuran skor frekuensi Strie Gravidarum pada ibu nifas yang diberikan minyak VCO diketahui rata-rata score frekuensi Strie Gravidarum pada ibu nifas adalah 2,93 dalam sehari (SD : 1.831) (SE: 0,473).

Striae gravidarum adalah retak pada kulit perut, pinggang dan paha. Akan menghilang perlahanlahan sekitar 6-12 bulan pascapersalinan. Kondisi ini akan dialami semua ibu hamil, termasuk yang kenaikan bobotnya hanya sedikit. Bedanya jika kenaikannya tidak drastis maka kulit hanya sedikit meregang sehingga keretakan yang terjadi tidak terlalu parah. ${ }^{1}$

Berdasarkan penelitian yang dilakukan oleh Susilowati (2016), tentang pengaruh minyak zaitun terhadap kejadian striae gravidarum pada ibu hamil. metode surveyanalitik dengan pendekatan eksperimen dengan rancangan pretest-posttest with control group.
Populasi dalam penelitian ini adalah seluruh ibu hamil primigravida dengan usia kehamilan 20-28 minggu jumlah sampel 30 responden yang dibagi menjadi masing-masing 15 responden kelompok eksperimen dan 15 responden kelompok kontrol. Dimana kelompok eksperimen diberikan intervensi minyak zaitun. sedangkan kelompok kontrol diberikan minyak VCO selama penelitian. Setelah dilakukan intervensi, ternyata didapatkan hasil bahwa nilai mean pada kelompok eksperimen lebih besar dari nilai mean pada kelompok kontrol.

2. Analisa Bivariat Hasil penelitian menunjukkan bahwa nilai rata-rata (mean) Strie Gravidarum pada ibu nifas yang diberikan minyak Zaitun adalah 3,13 dalam sehari dan standar deviasi adalah 1.642. Sedangkan nilai rata-rata (mean) Strie Gravidarum pada ibu nifas yang diberikan minyakVCO adalah 2,93 dalam sehari dan standar deviasi adalah 1.831 .

Hasil uji statistik dengan uji independent sample $t$ test diperoleh $p$ value $=0.007 \quad(p-$ value $<\mathrm{a}=0,05)$, hasil ini menunjukkan bahwa ada perbedaan yang signifikan antara pemberian minyak zaitun dan minyak VCO terhadap striae gravidarumpada ibu nifas. 
Jurnal Kebidanan Harapan Ibu Pekalongan

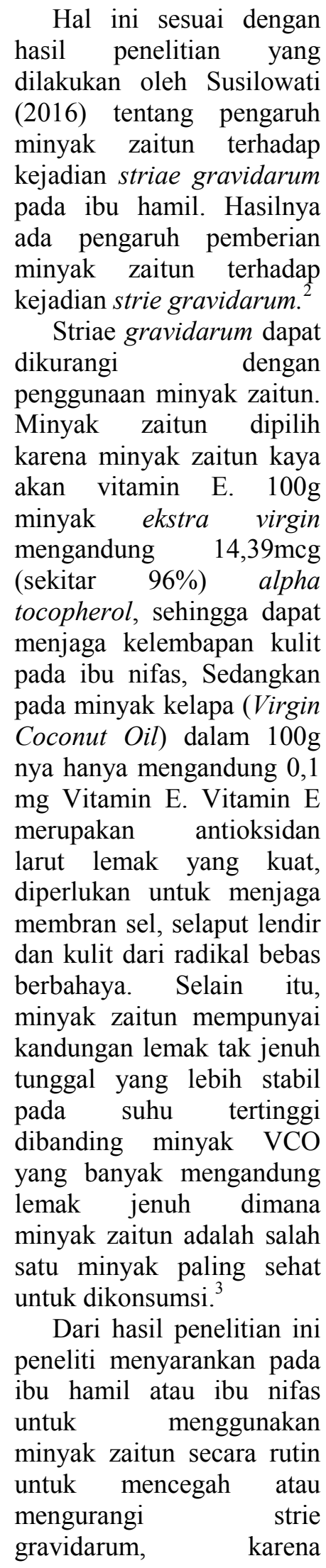

kandungan minyak zaitun dapat menjaga kelembaban pada kulit ibu hamil yang terjadi peregangan kulit yang sangat besar.

\section{Kesimpulan}

Berdasarkan hasil penelitian yang dilakukan pada 30 responden di Desa Blaru Kec.Pati Kab. Pati pada tahun 2020, dapat disimpulkan sebagai berikut:

a. Sebagian besar responden mempunyai Strie Gravidarum sebanyak 27 orang $(90 \%)$ dan responden yang tidak mempunyai Strie Gravidarum sebanyak 3 orang $(10 \%)$.

b. Skor frekuensi Strie Gravidarum pada ibu nifas yang diberikan minyak zaitun diketahui rata-rata score frekuensi Strie Gravidarum pada ibu nifas adalah 3,13 dalam sehari (SD : 1.642) (SE : 0,424). Sedangkan hasil pengukuran skor frekuensi Strie Gravidarum pada ibu nifas yang diberikan minyak VCO diketahui rata-rata score frekuensi Strie Gravidarum pada ibu nifas adalah 2,93 dalam sehari (SD : 1.831) (SE $: 0,473)$.

c. Ada perbedaan yang signifikan antara pemberian minyak zaitun dan minyak VCO terhadap striae gravidarum pada ibu nifas dengan nilai $p$ value $=0.007(p$-value $<\mathrm{a}=0,05)$. 
Jurnal Kebidanan Harapan Ibu Pekalongan

5. Daftar Pustaka

[1] Astuti, Hutari Puji. Buku Ajar Asuhan Kebidanan ibu I (Kehamilan). Yogyakarta: Rohima Press, 2012.

[2] Susilowati.. Pengaruh Pemberian Minyak Zaitun terhadap Kejadian Strie Gravidarum pada Ibu Hamil di BPS DA., S.Tr.Keb Bumi waras Bandar Lampung. Lampung: Universitas Malahayati, 2016.

[3] GenioFam. Mempersiapkan dan Menjaga Kehamilan. Yogyakarta: Leutika, 2010. 